The anti-inflammatory effect of microalgae Spirulina was studied in zymosan-induced arthritis in mice. Four days after the intra-articular injection of zymosan $(15 \mathrm{mg} / \mathrm{ml})$, Spirulina $(100$ and $400 \mathrm{mg} / \mathrm{kg}$ perorally) was administered to animals for 8 days. The mice were than killed and $\beta$-glucuronidase was measured in the synovial fluid. Each knee joint was totally removed for histopathological studies. Spirulina significantly reduced the levels of $\beta$-glucuronidase that had been increased by zymosan. Histopathological and ultrastructural studies showed inhibition of the inflammatory reaction, whereas no destruction of cartilage, well-preserved chondrocytes, and normal rough endoplasmic reticulum and mitochondria were seen. The anti-arthritic effect exerted by Spirulina as shown in this model may be at least partly due to the previously reported antiinflammatory and antioxidative properties of its constituent, phycocyanin. To our knowledge, this is the first report on the anti-inflammatory effect of Spirulina in an experimental model of arthritis.

Key words: Spirulina, Anti-inflammatory, Zymosan, Mice, Arthritis

\section{Inhibitory effects of Spirulina in zymosan-induced arthritis in mice}

\author{
Diadelis Remirez ${ }^{\mathrm{CA}}$, Ricardo González, \\ Nelson Merino, Sandra Rodriguez and \\ Odelsa Ancheta
}

Ozone International Center, Postbox 6412, Havana, Cuba

${ }^{\mathrm{CA}}$ Corresponding Author
Fax: +537210233
E-mail: ozono@infomed.sld.cu

\section{Introduction}

Spirulina is an unbranched, helicoidal, filamentous blue green algae or cyanobacterium that has a long history of use as food. There are reports that Spirulina was used traditionally by Mexicans during the Aztec civilization for over 1000 years and also used as food by the natives in the Lake Chad Area. ${ }^{1}$ Early interest in Spirulina focused mainly on its potential as a source of protein and vitamins, but recently more attention has been made to study its therapeutic use, and a number of published reports suggest beneficial effects of this microalgae in hypertension, its anti-cancer and immune suppressing actions, ${ }^{2-4}$ and its antioxidant properties. $^{5}$

Recently, we reported that phycocyanin, a biliprotein found in Spirulina, exerts a scavenging action against reactive oxygen species (ROS) as well as antiinflammatory activity demonstrated in various in vitro and in vivo models. ${ }^{6-8}$

Furthermore, phycocyanin also exerted anti-inflammatory and anti-arthritic effects in zymosan-induced arthritis in mice. ${ }^{9}$ Taking into account the former findings and the fact that phycocyanin is the most abundant pigment of Spirulina that represents approximately $20 \%$ of algal dry weight, ${ }^{10}$ we decided to elucidate whether Spirulina may exert similar inhibitory effects in this zymosan-induced arthritis model as that observed for phycocyanin.

\section{Materials and methods}

\section{Animals}

Female 6-week-old OF1 mice from National Center for Production of Laboratory Animals (CENPALAB, Havana, Cuba) were used in this study. They were housed under a $12 \mathrm{~h}$ light-dark cycle with room temperature maintained at $23^{\circ} \mathrm{C}$, humidity at $55 \%$, and food and water available ad libitum. The experiments were conducted in accordance with the ethical guidelines for investigations in laboratory animals and were approved by the Ethical Committee for Animal Experimentation of the National Center for Scientific Research. All reagents not specifically described were purchased from Sigma (St Louis, MO, USA). Microalgae Spirulina available with the trade name Spirulan was kindly provided by Genix Enterprise (Havana, Cuba).

\section{Zymosan-induced arthritis in mice}

The mice (10 per group) were injected intra-articularly with $10 \mu \mathrm{l}$ of a $15 \mathrm{mg} / \mathrm{ml}$ sterile suspension of zymosan. ${ }^{11}$ Four days after zymosan injection, a water suspension of Spirulina (100 and $400 \mathrm{mg} / \mathrm{kg}$ ) or triamcinolone $(10 \mathrm{mg} / \mathrm{kg})$, which was used as a reference drug, were administered orally on a daily basis, from days 4 to 12 . Mice were then killed by cervical dislocation and the synovial fluid of knee joints was sampled to measure the level of $\beta$-glucuronidase 
enzyme. Afterwards the knee joints were totally removed for histological and ultrastructural studies.

Appropriate controls of mice only treated with Spirulina and the vehicle were used.

\section{Determination of $\beta$-glucuronidase activity}

$\beta$-Glucuronidase activity was measured in the synovial fluid of knee joints of mice. ${ }^{12}$ The patellar ligament was cut and the synovial cavity incised, the total synovial fluid was then absorbed by means of small pieces of filter paper (No. 1575; Prolabo). The paper tips impregnated with synovial fluid were cut and deposited at the bottom of tubes containing $0.9 \mathrm{ml}$ of $50 \mathrm{mM}$ acetate buffer ( $\mathrm{pH}$ 4.5). The enzyme was measured in presence of its substrate (phenolphthalein mono- $\beta$-glucuronic acid, $20 \mathrm{mM}$ ), after incubation for $17 \mathrm{~h}$ at $37^{\circ} \mathrm{C}$. Then $2.5 \mathrm{vol}$ of $200 \mathrm{mM}$ glycine buffer ( $\mathrm{pH} 10.45$ ) was added to induce the coloration of the phenolphthalein produced by the enzymatic cleavage of the substrate. Samples were read at $540 \mathrm{~nm}$, the coloration being stable for at least $1 \mathrm{~h}$. Titers were based on comparisons with standard curves obtained with $\beta$-glucuronidase (type B- 1 from bovine liver). The values are expressed in units of enzymatic activity.

\section{Histological processing}

Knee joints were removed and fixed in phosphatebuffered formalin (10\%). The tissues were decalcified with $5 \%$ formic acid solution and thereafter they were processed and embedded in paraffin. Total joint sections $(6 \mu \mathrm{m})$ were prepared and stained with hematoxylin and eosin. Arthritis was assessed semiquantitatively in a standardized frontal section of the knee joint that included the presence of subsynovial inflammation, destruction of articular cartilage, and general destruction of the joint with pannus formation and bone erosion. ${ }^{13}$ These parameters were scored on a scale of $0-4$ as described elsewhere: ${ }^{9-13}$ 0 , no abnormalities, normal joint feature; 1 , marginal destruction of cartilage only and slight inflammation in the articular tissue; 2, extensive inflammation and moderate cartilage destruction with slight bone erosion, usually on one side of the joint only; 3 , extensive inflammation and significant destruction of both cartilage and bone; and 4, almost complete cartilage destruction with no intact cartilage left, almost complete loss of the general joint architecture with extensive pannus formation and bone erosion, extensive inflammation in the articular tissue, mainly by mononuclear cells (lymphocytes, plasma cells, macrophages), often accompanied by polymorphonuclear granulocytes. The score given to each joint is an average for the three histological sections through that joint.

Thus, the pathologist examined the parameters by a blinded procedure and classified the severity of the knee joint lesions in each mouse into five grades: grade 0 , normal; grade 1 , slight; grade 2 , moderate; grade 3 , marked; grade 4 , severe.

\section{Transmission electron microscopy}

Samples of articular cartilage were fixed in $3.2 \%$ glutaraldehyde in cacodilate buffer, post-fixed in $2 \%$ osmium tetroxide and embedded in Spurr resin. ${ }^{14}$ Sections were stained with lead citrate and uranil acetate, ${ }^{15}$ and observed in a JEOL JEM-100s Electron Microscope (Japan).

\section{Statistical analysis}

Data are presented as mean \pm standard deviation. Mean differences between groups were compared by oneway analysis of variance with the Duncan's test. The level of statistical significance was taken at $p<0.05$.

\section{Results}

\section{Spirulina effect on zymosan-induced arthritis}

Zymosan-induced arthritis resulted in a significant increase of $\beta$-glucuronidase levels, which were decreased by Spirulina at doses of 100 and $400 \mathrm{mg} / \mathrm{kg}$ per-orally (p.o.). This effect was dose dependent (Table 1). Triamcinolone almost completely abolished enhanced $\beta$-glucuronidase activity in the synovial fluid of zymosan-treated animals. Daily doses of 100 and $400 \mathrm{mg} / \mathrm{kg}$ suppressed the enzymatic activity by 78.7 and $89.2 \%$, respectively (Table 1 ).

Table 1. Effect of Spirulina on $\beta$-glucuronidase activity in mice knee joint synovial fluid

\begin{tabular}{|c|c|c|c|}
\hline Kind of treatment & Doses & $\beta$-Glucuronidase (U) & Inhibition $(\%$ \\
\hline Saline & & $0.70 \pm 0.25$ & - \\
\hline Zymosan & $15 \mathrm{mg} / \mathrm{ml}$ & $5.15 \pm 1.20$ & - \\
\hline Triamcinolone + zymosan & $10 \mathrm{mg} / \mathrm{kg}$ & $1.00 \pm 0.20 *$ & 94.1 \\
\hline Spirulina + zymosan & $100 \mathrm{mg} / \mathrm{kg}+15 \mathrm{mg} / \mathrm{kg}$ & $2.82 \pm 0.68 *$ & 78.7 \\
\hline Spirulina + zymosan & $400 \mathrm{mg} / \mathrm{kg}+15 \mathrm{mg} / \mathrm{kg}$ & $1.80 \pm 0.19 *$ & 89.2 \\
\hline
\end{tabular}

Mice were killed $24 \mathrm{~h}$ after the last administration of Spirulina. It was administered 4 days after zymosan treatment for 12 days. Triamcinolone was used as a positive control drug in this test. Values are means from groups of 10 mice \pm standard error.

${ }^{*} p<0.05$ versus group treated only with zymosan. 


\section{Histopathological studies}

In agreement with these findings, histological evaluation revealed that the group treated with zymosan showed severe destruction of cartilage with loss of the general joint architecture and pannus formation. There was erosion of bone structures accompanied by severe inflammation of articular tissues (Grades 3 and 4) (Fig. 1a and Table 2).

Spirulina treatment $(100$ and $400 \mathrm{mg} / \mathrm{kg}$ p.o. $)$ revealed a marked decrease of histology score (Grades 1 and 2), the inflammatory reaction was substantially reduced and there was no destruction of general joint architecture or pannus formation. Also, a reduction of bone erosion was observed (Fig. 1b). At the Spirulina doses of 100 and $400 \mathrm{mg} / \mathrm{kg}, 60$ and $80 \%$ of the treated mice, respectively, only showed slight lesions on the joints (Table 2). Even greater protective effects were observed with the reference drug, triancinolone (Table 2).

\section{Ultrastructural studies}

Tibial articular cartilage of mice treated with zymosan showed chondrocytes with ultrastructural changes in the mitochondria, loss of cristae and swollen matrix. Separation between collagen fiber bundles were also observed (Fig. 2a).

On the contrary, the cartilage of mice treated with zymosan plus Spirulina ( $400 \mathrm{mg} / \mathrm{kg}$ p.o.) showed wellpreserved chondrocytes with normal rough endoplasmic reticulum. The collagen fibers present a normal arrangement (Fig. 2b).

\section{Discussion}

Rheumatoid arthritis is a chronic systemic autoimmune inflammatory disease characterized by progressive joint damage and, in its later stages, cartilage destruction. The current concept of the pathophysiology of this disease is that the inflammation and tissue destruction result from an unregulated cascade of complex cell-to-cell interactions, initiated by macrophage activation and induced by some inflammatory triggers. ${ }^{16}$ Zymosan, a product consisting of purified

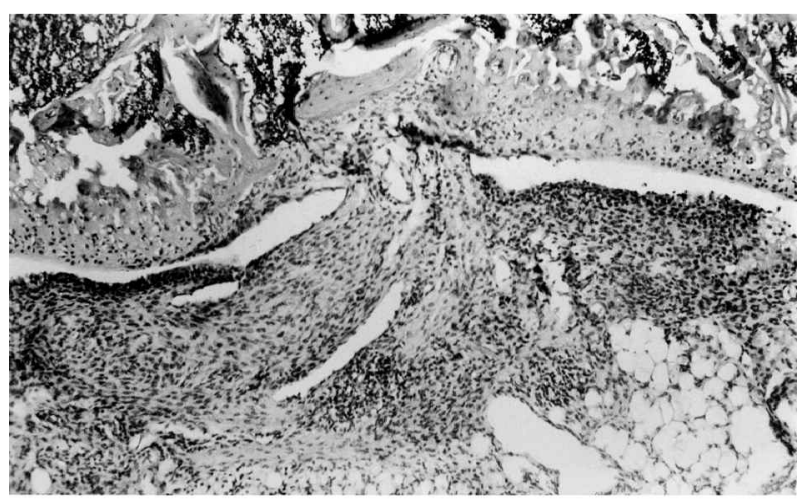

(a)

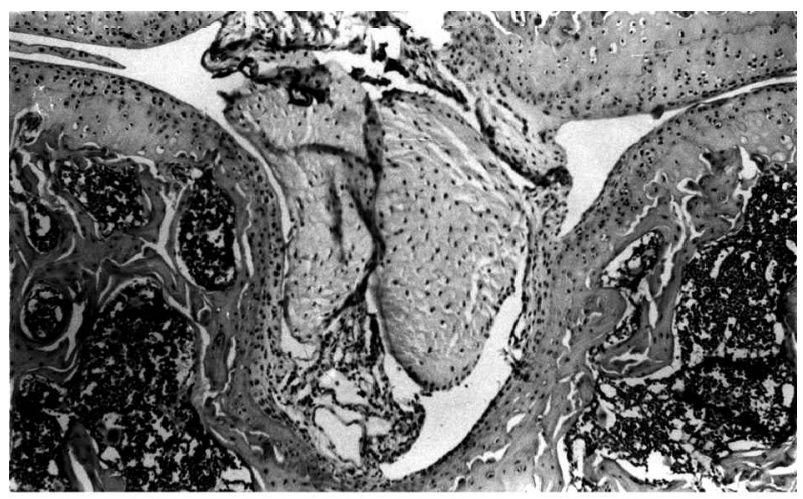

(b)

FIG. 1. (a) Histological section of the knee joint infected with $15 \mathrm{mg} / \mathrm{ml}$ of zymosan. Extensive pannus formation with erosion of joint cartilage and bone. Hematoxylin and eosin, 100x. (b) Mouse treated with zymosan plus Spirulina, $400 \mathrm{mg} / \mathrm{kg}$ p.o. Histology of the knee shows only minimal inflammatory reaction. Hematoxylin and eosin, 100x.

baker's yeast ghost cells, induces inflammatory processes in which the macrophages play an important role, and the activation of the synthesis of cytokines and various pro-inflammatory mediators such as prostaglandins and leukotrienes occurs. ${ }^{17}$ Zymosan also activates complement via an alternative pathway, and induces secretion of lysosomal enzymes and ROS generation from the macrophages. ${ }^{18}$ Currently, it is recognized that ROS such as $\mathrm{OH}^{\circ}, \mathrm{H}_{2} \mathrm{O}_{2}$ and $\mathrm{HOCl}$ are strongly involved in RA. ${ }^{19}$

In accordance with these findings, some antioxidant agents such as $\mathrm{N}$-acetylcysteine, ${ }^{20}$ ketoprofen $^{21}$ and

Table 2. Articular histological lesions of the knee in zymosan-induced arthritis in mice treated with Spirulina

\begin{tabular}{lccccc}
\hline Kind of treatment & Dose & $\begin{array}{c}\text { Grade } 0 \\
(\%)\end{array}$ & $\begin{array}{c}\text { Grade } 1 \\
(\%)\end{array}$ & $\begin{array}{c}\text { Grade 2 } \\
(\%)\end{array}$ & $\begin{array}{c}\text { Grade } 3 \\
(\%)\end{array}$ \\
\hline Saline & & 100 & - & - & - \\
Zymosan & $15 \mathrm{mg} / \mathrm{ml}$ & - & - & - & 50 \\
Triancinolone + zymosan & $10 \mathrm{mg} / \mathrm{kg}$ & 90 & 10 & - & - \\
Spirulina + zymosan & $100 \mathrm{mg} / \mathrm{kg}$ & - & 60 & 40 & - \\
Spirulina + zymosan & $400 \mathrm{mg} / \mathrm{kg}$ & - & 80 & 20 & - \\
\hline
\end{tabular}

Histological studies were read and scored on a scale of $0-4$ according to the severity of the lesions: grade 0 , normal; grade 1 , slight; grade 2, moderate; grade 3, marked; grade 4, severe. The animals in each group were assessed for lesions. Triamcinolone was used as reference drug. 


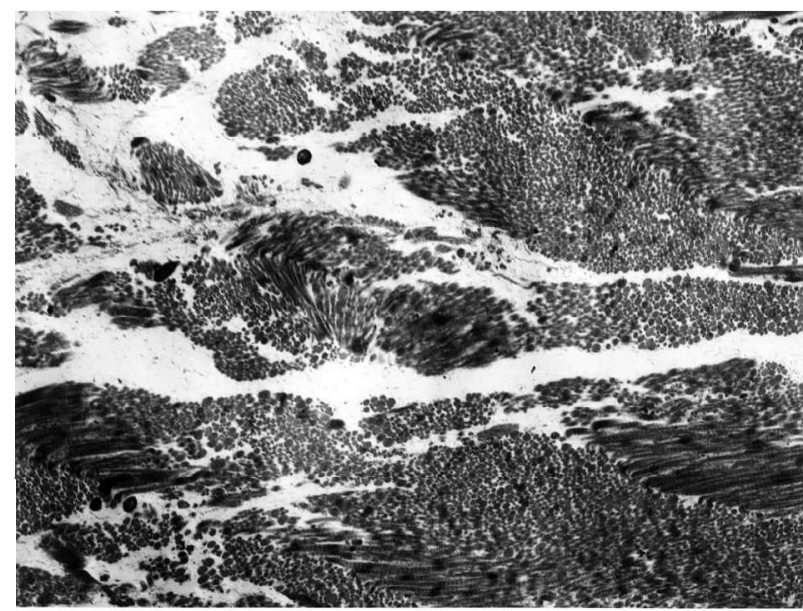

(a)

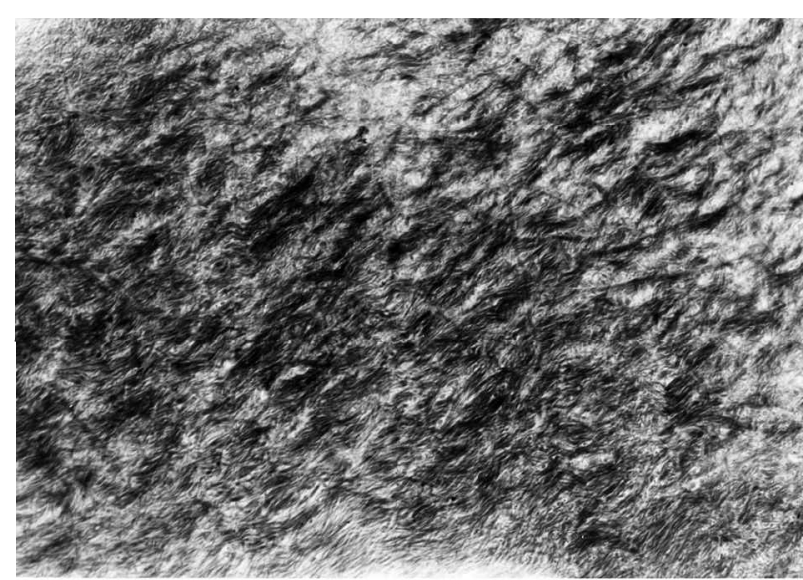

(b)

FIG. 2. (a) Transmission electron microscopy image of tibial cartilage treated with $15 \mathrm{mg} / \mathrm{ml}$ of zymosan. Edema between the collagen fibrils package is shown. 12,000×. (b) Transmission electron microscopy image of tibial cartilage treated with $15 \mathrm{mg} / \mathrm{ml}$ of zymosan plus $400 \mathrm{mg} / \mathrm{kg}$ Spirulina. A normal arranbgement of collagen fibrils is observed. 12,000×.

ebselen $^{22}$ exerted protective effects in some arthritis models.

Recently, we reported that phycocyanin has antioxidant properties. ${ }^{6}$ It was able to scavenge alkoxy and hydroxyl radicals, and also inhibited hepatic microsomal lipid peroxidation induced by $\mathrm{Fe}^{+2}$-ascorbic acid, the luminol-amplified chemiluminescent response of PMNLs stimulated with opsonized zymosan. Phycocianin also inhibited, in a dose-dependent fashion, the inflammatory response in zymosaninduced arthritis in mice. Furthermore, the biliprotein also inhibited edema and leukotriene $\mathrm{B}_{4}$ and prostaglandin $\mathrm{E}_{2}$ generation in arachidonic acidinduced ear edema in mice. ${ }^{23,24}$

Taking into account the former findings, it is conceivable that the anti-inflammatory and antiarthritic effects of Spirulina already described may be due mainly to antioxidant and anti-inflammatory activities of its constituent phycocyanin. Some evidence support this view: (1) in our hands, phycocyanin exerted protective effects in zymosan-induced arthritis at doses of 25, 50 and $100 \mathrm{mg} / \mathrm{kg}$ p.o., whereas under the same experimental conditions Spirulina exerted its inhibitory effects in this model at greater doses (100 and $400 \mathrm{mg} / \mathrm{kg}$, p.o.), which correlates with $20-25 \%$ that represents phycocyanin in the composition of Spirulina; ${ }^{10}(2)$ our results do not provide any evidence in favor of pharmacological synergism of phycocyanin with other constituents of Spirulina with antioxidant and anti-inflammatory properties such as $\beta$-carotene, phenolic compounds and the essential polyunsaturated fatty acids. However, these substances are available in Spirulina in much lower concentrations than phycocyanin. ${ }^{5,25}$ Nevertheless, a minor contribution of the former compounds to anti-inflammatory effects of Spirulina cannot be excluded.

In conclusion, Spirulina exerts anti-inflammatory effects in experimental arthritis and, taking into account that the microalgae is commonly used as food supplement and its safety as human food has been established through various toxicological studies, ${ }^{26,27}$ we believe that Spirulina merits further pre-clinical and clinical studies to determine its place as potential drug for the treatment of rheumatoid arthritis and other inflammatory diseases.

\section{References}

1. Ciferri $O$, Tiboni $O$. The biochemistry and industrial potential of Spirulina. Ann Rev Microbiol 1985, 39: 503-526.

2. Iwata K, Inayama T, Kato T. Effects of Spirulina platensis on plasma lipoprotein lipase activity in fructose-induced hyperlipidemic rats. $J \mathbf{N u t r}$ Sci Vitaminol 1990, 36: 165-171.

3. Belay A, Ota Y, Miyakawa K, Shimamatsu H. Current knowledge on potential health benefits of Spirulina. J Appl Pbycol 1993, 5: 235-241.

4. Hayashi O, Katoh T, Okuwaki Y. Enhancement of antibody production in mice by dietary Spirulina. J Nutr Sci Vitaminol 1994, 40: 431-441.

5. Miranda MS, Cintra RG, Barros SBM, Mancini-Filho J. Antioxidant activity of the microalgae Spirulina máxima. Braz J Med Biol Res 1998, 31: 1075-1079.

6. Romay Ch, Armesto J, Remirez D, González R, Ledón N, García I. Antioxidant and anti-inflammatory properties of c-phycocyanin from blue-green algae. Inflamm Res 1998, 47: 36-41.

7. Romay Ch, Ledón N, González R. Further studies on anti-inflammatory activity of phycocyanin in some animal models of inflammation. Inflamm Res 1998, 47: 334-338.

8. González R, Rodńguez S, Romay Ch, Ancheta O, González A, Armesto J, Remirez D, Merino N. Anti-inflammatory activity of phycocyanin extract in acetic acid-induced colitis in rats. Pharmacol Res 1999, 39: 55-59.

9. Remirez D, González A, Merino N, González R, Ancheta O, Romay Ch, Rodríguez $\mathrm{S}$. Effect of phycocyanin in zymosan-induced arthritis in mice. Drug Dev Res 1999, 48: 70-75.

10. Richmond A. Large scale microalgal culture and applications. In: Chapman R, ed. Progress in Phycological Research, Vol. 7. Biopress Ltd, 1990 .

11. Keystone EC, Schorlemmer HU, Pope C, Allison AC. Zymosan-induced arthritis. A model of chronic proliferative arthritis following activation of the alternative pathway of complement. Arthritis Rbeum 1977, 20: 1396-1401.

12. Folliard F, Terlain A. A novel method for the sampling of synovial fluid in mice. Assay of a synovial lysosomal enzyme in zymosan induced arthritis. Agents Actions 1998, 25: 139-145.

13. Beckman N, Bruttel K, Schuurman H, Mir A. Effects of sandimmune neoral on collagen-induced arthritis in DA rats: characterization by high resolution three-dimensional magnetic resonance imaging and by histology. J Magn Reson 1998, 131: 8-16.

14. Spurr ERA. A low viscosity epoxy resin embedding medium for electron microscopy. J Ultrastr Res 1969, 26: 31-35.

15. Reynold ES. The use of lead citrate at high $\mathrm{pH}$ as an electron-opaque stain in electron microscopy. J Cell Biol 1963, 17: 208-213.

16. Chikanza IC, Jawed S, Naughton D, Blake DR. Why do we need new treatments for rheumatoid arthritis? J Pharm Pharmacol 1998, 50: 357-369. 
17. Cuzzocrea S, Costantino G, Caputi AP. Protective effect of $\mathrm{N}$-acetylcysteine on cellular energy depletion in a non-septic shock model induced by zymosan in the rat. Shock 1999, 11: 143-148.

18. Allison AC. Role of macrophage activation in the pathogenesis of chronic inflammation and its pharmacological control. Adv Inflamm Res 1984 7: 201-216.

19. Miesel R, Zuber M. Elevated levels of xanthine oxidase in serum of patients with inflammatory and autoimmune diseases. Inflammation 1993, 17: 551-561.

20. Kröger H, Miesel R, Dietrich A, Ohde M, Altrichter S, Braun C, Ockenfels $\mathrm{H}$. Suppression of type II collagen-induced arthritis by $\mathrm{N}$-acetyl-L-cysteine in mice. Gen Pharmac 1997, 29: 671-674.

21. Billany MR, Denman S, Jameel S, Sugden JK. Topical anti-rheumatic agents as hydroxyl radical scavengers. Int J Pharm 1995, 124: 279-283.

22. Schewe T. Molecular actions of ebselen, an anti-inflammatory antioxidant. Gen Pharmac 1995, 26: 1153-1169.
23. Romay Ch, Ledón N, González R. Phycocyanin extract reduces leukotriene $\mathrm{B}_{4}$ levels in arachidonic acid-induced mouse ear inflammation test. J Pharm Pharmacol 1991, 51: 641-642.

24. Romay Ch, Ledón N, González R. Effects of phycocyanin extract on prostaglandin $\mathrm{E}_{2}$ levels in mouse ear inflammation test. ArzneimForsch/ DrugRes 2000, 50: 1106-1109.

25. Henrikson R. Microalgae Spirulina. Barcelona: Urano, 1994.

26. Chamorro GA, Salazar M. Dominant letal assay of Spirulina máxima in male CD-1 mice after short-term and prolonged-term feeding. $J$ Food Protect 1989, 52: 125-127.

27. Salazar M, Chamorro GA. Effect of Spirulina máxima consumption on reproduction and peri- and postnatal development in rats. Food Chem Toxicol 1996, 34: 353-359.

\section{Received 25 September 2001}

Accepted 21 January 2002 


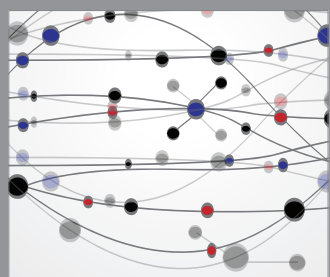

The Scientific World Journal
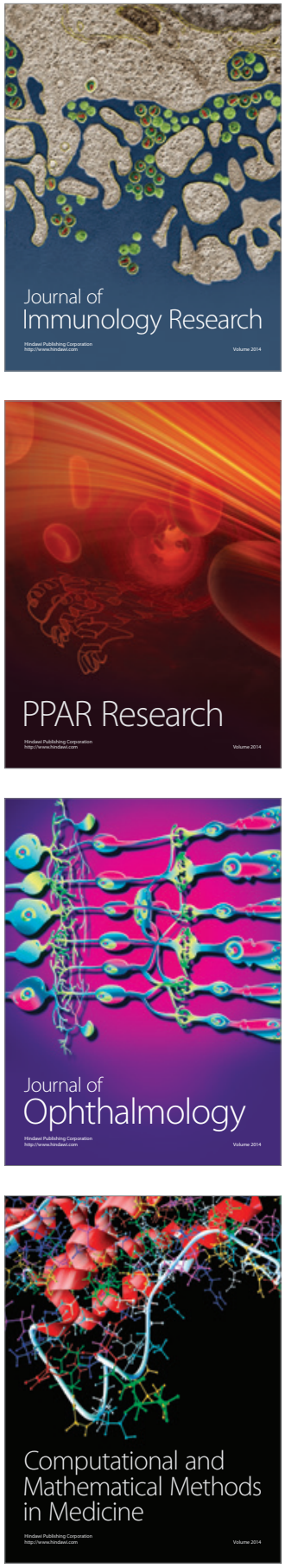

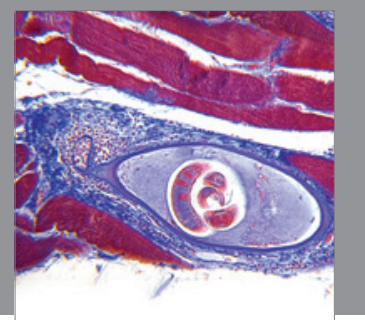

Gastroenterology

Research and Practice
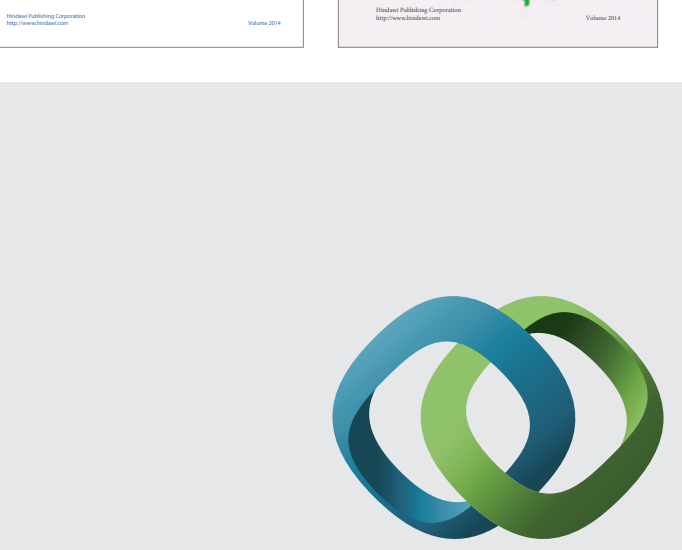

\section{Hindawi}

Submit your manuscripts at

http://www.hindawi.com
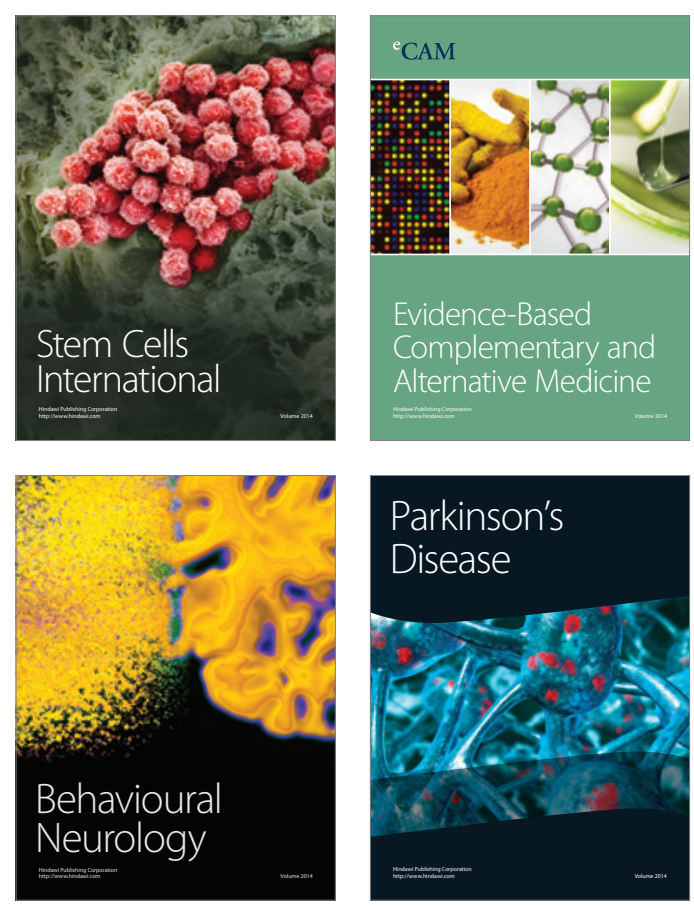

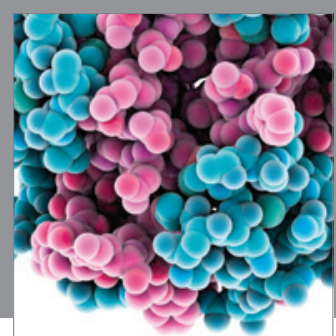

Journal of
Diabetes Research

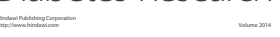

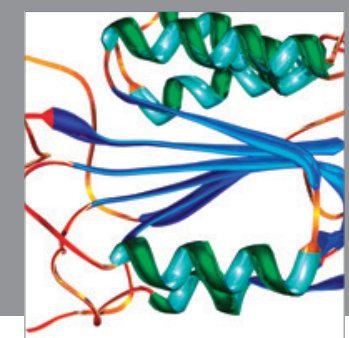

Disease Markers
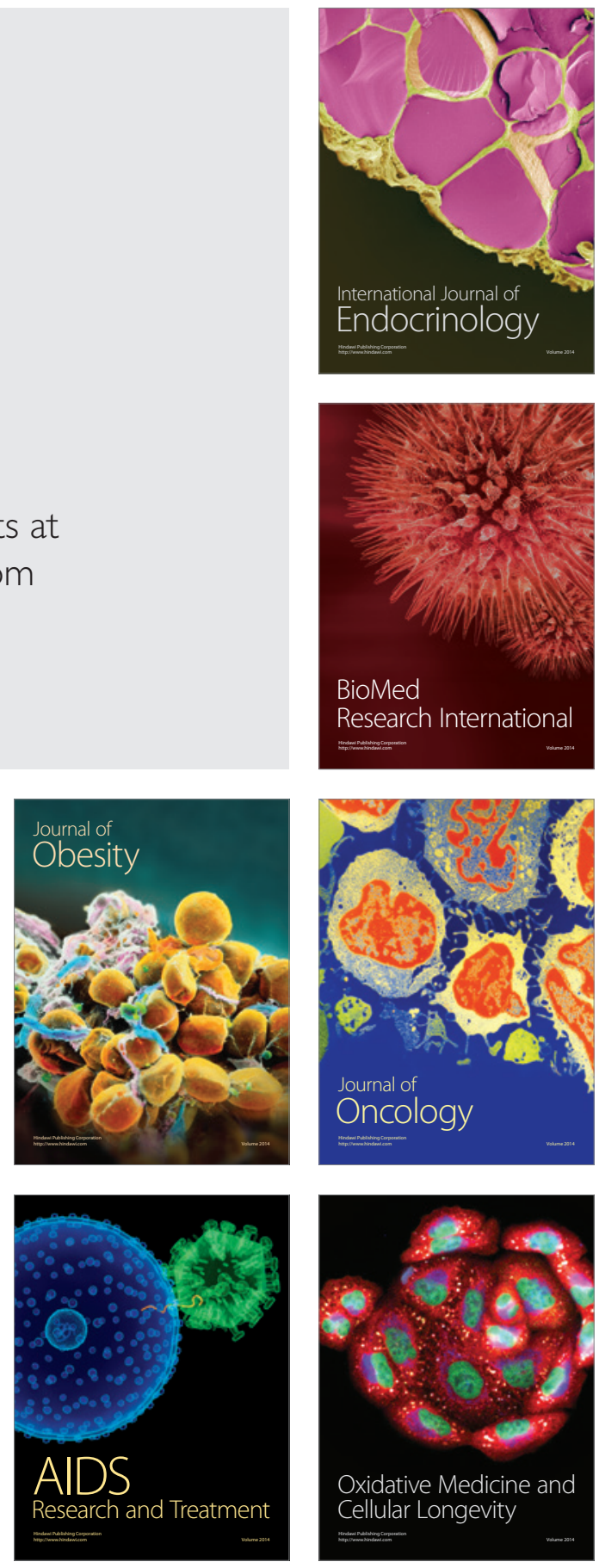